\title{
Direct arylations of electron-deficient (hetero)arenes with aryl or alkenyl tosylates and mesylates $\dagger \ddagger$
}

\author{
Lutz Ackermann* and Sabine Fenner
}

\author{
Received 4th July 2010, Accepted 1st September 2010 \\ DOI: $10.1039 /$ c0cc02360d
}

A palladium catalyst derived from the ligand X-Phos enabled generally applicable direct arylations of electron-deficient heteroarenes and arenes with aryl and alkenyl tosylates or mesylates.

Biaryls are indispensable structural motifs in inter alia bioactive small molecules or functional materials. Traditionally, their syntheses strongly rely on cross-coupling reactions with organometallic or main group-element nucleophiles, ${ }^{1,2}$ which continue to be particularly challenging with electron-deficient nucleophiles. ${ }^{3,4}$ However, recent progress is represented by the development of transition-metal-catalyzed direct arylations, which resulted in more sustainable methods for the preparation of biaryl scaffolds. ${ }^{5,6}$ These methods enable a streamlining of organic synthesis by avoiding substrate pre-activation through the use of simple (hetero)arenes, which predominantly serve as surrogates for difficult to access organometallic reagents.

Catalyzed direct arylations through $\mathrm{C}-\mathrm{H}$ bond cleavages have been thoroughly explored with aryl halides or aryl triflates as electrophilic coupling partners. ${ }^{5}$ Contrarily, aryl tosylates are generally more attractive electrophiles, since they are moisture-stable, inexpensive and easily prepared from readily available phenols. ${ }^{7,8}$ Unfortunately, their remarkable stabilities render these electrophiles significantly less reactive, and thus highly challenging in catalytic arylation reactions. As a consequence, direct arylations with aryl tosylates are as of yet restricted to ruthenium-catalyzed functionalizations of arenes displaying Lewis-basic directing groups, ${ }^{9}$ or palladiumcatalyzed $\mathrm{C}-\mathrm{H}$ functionalizations on electron-rich azoles. ${ }^{10} \mathrm{On}$ the contrary, we wish to report herein on the development of first direct arylations of electron-deficient (hetero)arenes ${ }^{11}$ with difficult to activate aryl tosylates. Notably, the optimized catalytic system also proved amenable to the first general use of more atom-economical aryl mesylates as electrophiles, and allowed for direct functionalizations of electron-deficient arenes.

Our studies commenced with applying reaction conditions previously established for $\mathrm{C}-\mathrm{H}$ functionalizations of electronrich azoles ${ }^{10}$ to the conversion of electron-deficient $N$-oxide 1a with aryl tosylates 2 (Scheme 1). Unfortunately, only an unsatisfactory low conversion of heteroarene 1a was observed

Institut fuer Organische und Biomolekulare Chemie,

Georg-August-Universitaet, Tammannstrasse 2, 37077 Goettingen,

Germany.E-mail: Lutz.Ackermann@chemie.uni-goettingen.de;

Fax: +49551396777

$\dagger$ This article is part of the 'Emerging Investigators' themed issue for ChemComm.

$\ddagger$ Electronic supplementary information (ESI) available: Optimization of reaction conditions, experimental procedures and characterization data. See DOI: $10.1039 / \mathrm{c} 0 \mathrm{cc} 02360 \mathrm{~d}$

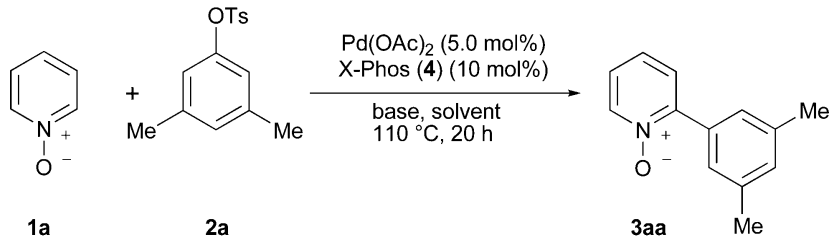

$\mathrm{DMF} / t-\mathrm{BuOH}(2: 1), \mathrm{K}_{2} \mathrm{CO}_{3}: \quad 9 \%$ $\mathrm{PhMe} / \mathrm{t}-\mathrm{BuOH}(2: 1), \mathrm{CsF}: \quad 64 \%$

Scheme 1 Summary of optimization studies on the direct arylation of heteroarene 1a with aryl tosylate 2a (see ESI $\ddagger$; X-Phos $(\mathbf{4})$ = 2-(dicyclohexylphosphino)-2', 4',6'-triisopropylbiphenyl).

here. Subsequent detailed optimization studies (see ESI $\ddagger$ ) highlighted that superior reaction conditions involved the use of $\mathrm{X}$-Phos (4) as the ligand, a $t-\mathrm{BuOH} /$ toluene solvent mixture and $\mathrm{CsF}$ as the base. ${ }^{12}$ Further, it is noteworthy that the addition of cocatalytic amounts of pivalic acid did not have a beneficial effect.

With optimized reaction conditions in hand, we probed the scope of direct arylations of pyridine $N$-oxides 1 with representative moisture-stable aryl tosylates $\mathbf{2}$ as electrophiles (Scheme 2). Notably, both electron-deficient as well as electronrich, hence electronically deactivated aryl tosylates $\mathbf{2}$ provided the desired products $\mathbf{3}$, as did ortho-substituted aryl or heteroaryl tosylates. Additionally, the diastereoselective formation of alkenes proved viable, as showcased with the synthesis of $N$-oxide 3aj. All reactions featured a high chemoselectivity in that the mono-arylated products 3 were exclusively formed. Furthermore, intramolecular competition experiments indicated a dependence of regioselectivity on $\mathrm{C}-\mathrm{H}$ bond acidity, which

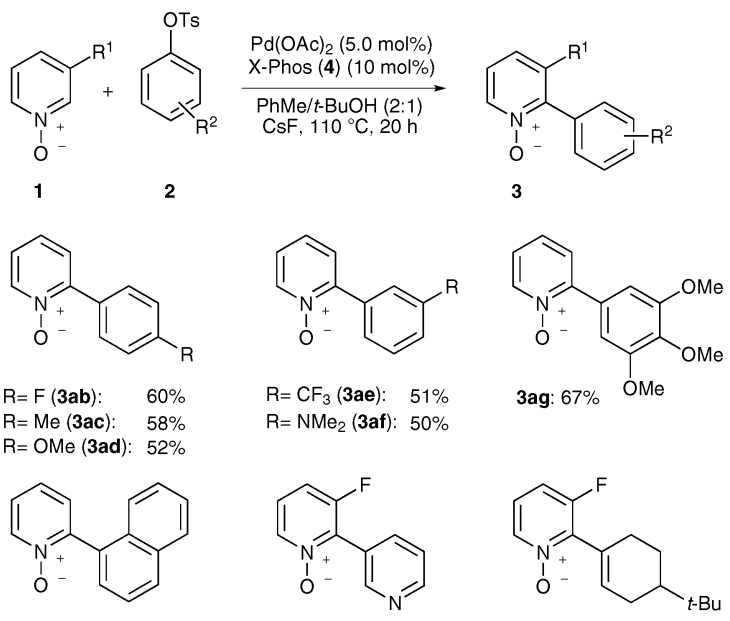

3ah: $60 \%$

3ai: $64 \%$

Scheme 2 Direct arylations of electron-deficient pyridine $N$-oxides 1 . 
led to the selective formation of $N$-oxides 3ai and 3aj as the sole products.

Subsequently, we were pleased to find that diazine $N$-oxides 1 were also suitable substrates for direct arylations with aryl tosylates $\mathbf{2}$ under the optimized reaction conditions (Scheme 3). Hence, products 3ak-3ap and 3aq-3at derived from pyridazine or pyrazine $N$-oxides $\mathbf{1}$, respectively, were obtained from diversely-substituted aryl tosylates $\mathbf{2}$. Moreover, mono-arylated quinoline and quinoxaline $N$-oxides 3au-3av and 3aw-3ba, respectively, could be selectively prepared likewise. In addition to aryl tosylates, an alkenylic electrophile was exploited for a selective access to alkene 3ba.

Aryl mesylates $\mathbf{5}$ have significantly lower molecular weights than the corresponding tosylates $\mathbf{2}$, and thus improve the atom-economy of direct arylations. Thus far, only two examples of direct arylations with aryl mesylates were reported, notably employing electron-deficient, hence activated electrophiles $\mathbf{5}^{10}$ Therefore, we were pleased to observe that various aryl mesylates $\mathbf{5}$ could be successfully used for direct arylations of pyridine $\mathrm{N}$-oxide $\mathbf{1 b}$, including electron-rich and/or orthosubstituted derivatives 5 (Scheme 4).

Finally, the optimized catalytic system also allowed for direct arylations of electron-deficient arenes ${ }^{13}$ with deactivated

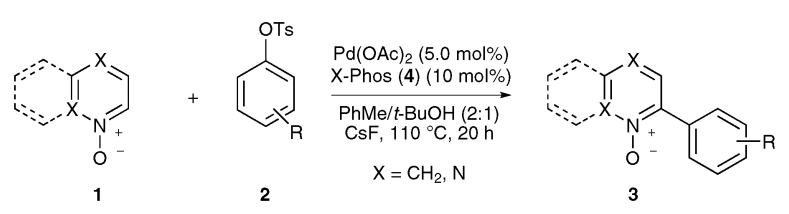<smiles>[N+]=[N+]([O-])c1cc(-c2cccn[n+]2[O-])cc([N+](=O)[O-])c1</smiles><smiles>COc1cc(-c2cccn[n+]2[O-])cc(OC)c1OC</smiles><smiles>CN(C)c1cccc(-c2cccn[n+]2[O-])c1</smiles>

3ak: $74 \%$<smiles>O=Cc1ccc(-c2cccn[n+]2[O-])cc1</smiles><smiles>[O-][n+]1ncccc1-c1cccc2ccccc12</smiles>
3ap: $71 \%$ $\mathrm{R}=\mathrm{Ph}(\mathbf{3 a 0}): 50 \%$<smiles>O=[N+]([O-])c1cc(-c2cncc[n+]2[O-])cc([N+](=O)[O-])c1</smiles><smiles>COc1cc(-c2cncc[n+]2[O-])cc(OC)c1OC</smiles><smiles>O=C(O)c1ccc(-c2cncc[n+]2[O-])cc1</smiles>
$R=E t(3 a r): 57 \%$<smiles>COc1cc(-c2ccc3ccccc3[n+]2[O-])cc(OC)c1OC</smiles>
3as: $51 \%$ 3at: $62 \%$ 3au: $69 \%$<smiles>[O-][n+]1c(-c2ccc(F)cc2)ccc2ccccc21</smiles><smiles>COc1cc(-c2cnc3ccccc3[n+]2[O-])cc([N+]([O-])([O-])[O-])c1</smiles><smiles>[O-][n+]1c(-c2cccc3ccccc23)cnc2ccccc21</smiles>

3ay: $73 \%$<smiles>O=C(Oc1ccccc1)c1ccc(-c2cnc3ccccc3[n+]2[O-])cc1</smiles>

3az: $68 \%$

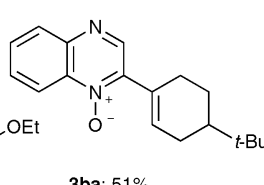

3ba: $51 \%$
Scheme 3 Scope of direct arylations with electron-deficient $N$-oxides 1.

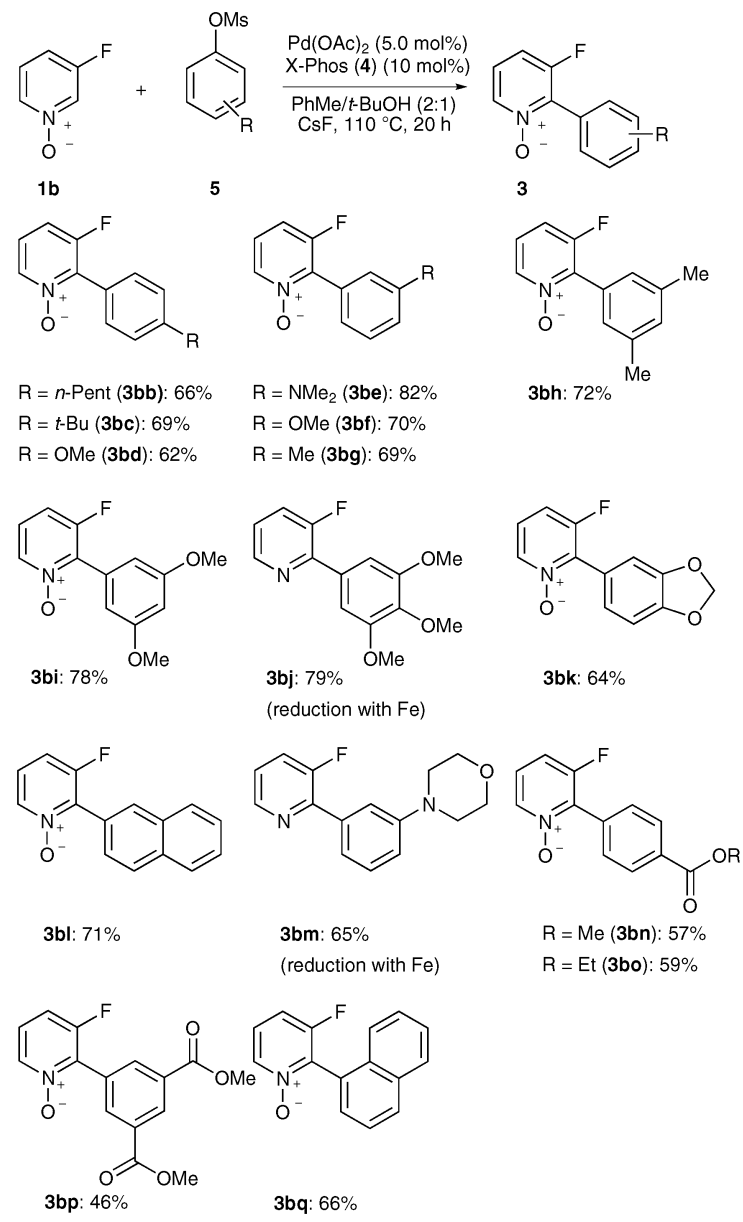

Scheme 4 Direct arylations of $N$-oxide $\mathbf{1 b}$ with aryl mesylates $\mathbf{5}$.

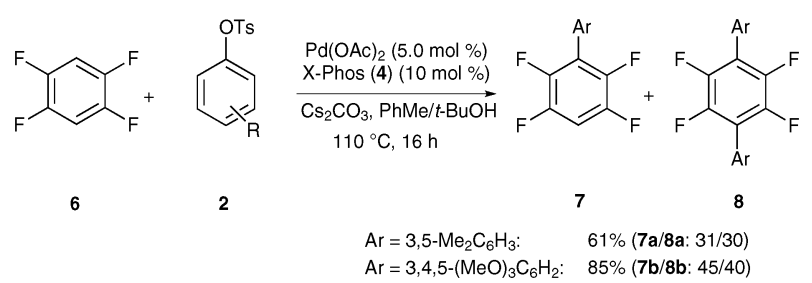

Scheme 5 Direct arylations of arene 6 with electron-rich aryl tosylates $\mathbf{2}$.

aryl tosylates, as illustrated for $\mathrm{C}-\mathrm{H}$ bond functionalizations on arene 6 (Scheme 5).

In conclusion, we have developed a catalytic system for unprecedented direct arylations of electron-deficient heteroarenes with moisture-stable aryl tosylates. Importantly, the optimized palladium catalyst also enabled first general direct arylations with atom-economical aryl mesylates, and was found applicable to direct functionalizations of electron-deficient arenes.

\section{Notes and references}

1 Metal-Catalyzed Cross-Coupling Reactions, ed. A. de Meijere and F. Diederich, Wiley-VCH, Weinheim, 2004.

2 J. Tsuji, Palladium Reagents and Catalysts, Wiley, Chichester, 2004.

3 For representative examples of traditional cross-coupling reactions with 2-pyridyl organometallics, see: (a) Suzuki-Miyaura: D. M. Knapp, E. P. Gillis and M. D. Burke, J. Am. Chem. Soc., 2009, 131, 6961-6963; (b) L. Ackermann and H. K. Potukuchi, 
Synlett, 2009, 2852-2856; (c) K. L. Billingsley and S. L. Buchwald, Angew. Chem., Int. Ed., 2008, 47, 4695-4698; (d) Kumada-Corriu: L. Ackermann, H. K. Potukuchi, A. R. Kapdi and C. Schulzke, Chem.-Eur. J., 2010, 16, 3300-3303; (e) Stille: R. Wittenberg, J. Srogl, M. Egi and L. S. Liebeskind, Org. Lett., 2003, 5, 3033-3035; (f) Negishi: B. M. Coleridge, C. S. Bello, D. H. Ellenberger and A. Leitner, Tetrahedron Lett., 2010, 51, 357-359, and references cited therein.

4 L.-C. Campeau and K. Fagnou, Chem. Soc. Rev., 2007, 36, 1058-1068.

5 Select recent reviews: (a) L. Ackermann, Chem. Commun., 2010, 46, 4866-4877; (b) C.-L. Sun, B.-J. Li and Z.-J. Shi, Chem. Commun., 2010, 46, 677-685; (c) L. Ackermann, R. Vicente and A. R. Kapdi, Angew. Chem., Int. Ed., 2009, 48, 9792-9826; (d) X. Chen, K. M. Engle, D.-H. Wang and J.-Q. Yu, Angew. Chem., Int. Ed., 2009, 48, 5094-5115; (e) O. Daugulis, H.-Q. Do and D. Shabashov, Acc. Chem. Res., 2009, 42, 1074-1086; (f) P. Thansandote and M. Lautens, Chem.-Eur. J., 2009, 15, 5874-5883; $(g)$ F. Bellina and R. Rossi, Tetrahedron, 2009, 65, 10269-10310; (h) J. C. Lewis, R. G. Bergman and J. A. Ellman, Acc. Chem. Res., 2008, 41, 1013-1025; (i) T. Satoh and M. Miura, Chem. Lett., 2007, 200-205; (j) I. V. Seregin and V. Gevorgyan, Chem. Soc. Rev., 2007, 36, 1173-1193; (k) S. Pascual, P. de Mendoza and A. M. Echavarren, Org. Biomol. Chem., 2007, 5, 2727-2734; (l) L. Ackermann, Synlett, 2007, 507-526; (m) L.-C. Campeau, D. R. Stuart and K. Fagnou, Aldrichimica Acta, 2007, 40, 35-41.

6 Modern Arylation Methods, ed. L. Ackermann, Wiley-VCH, Weinheim, 2009.

7 For representative examples of conventional palladium-catalyzed coupling reactions between aryl tosylates and pre-activated (hetero)arenes, see: (a) Suzuki-Miyaura couplings: C. M. So, C. Po Lau and F. Y. Kwong, Angew. Chem., Int. Ed., 2008, 47, 8059-8063; (b) H. N. Nguyen, X. Huang and S. L. Buchwald, J. Am. Chem. Soc., 2003, 125, 11818-11819; (c) Negishi couplings: J. Zhou and G. C. Fu, J. Am. Chem. Soc., 2003, 125, 12527-12530; (d) Kumada-Corriu couplings: L. Ackermann and A. Althammer, Org. Lett., 2006, 8, 3457-3460; (e) A. H. Roy and J. F. Hartwig, J. Am. Chem. Soc., 2003, 125, 8704-8705; ( $f$ ) Hiyama couplings: L. Zhang and J. Wu, J. Am. Chem. Soc., 2008, 130, 12250-12251, and references cited therein.

8 Direct arylations and alkenylations with sulfamates: L. Ackermann, S. Barfüsser and J. Pospech, Org. Lett., 2010, 12, 724-726.

9 (a) L. Ackermann, A. Althammer and R. Born, Angew. Chem., Int. Ed., 2006, 45, 2619-2622; (b) L. Ackermann, R. Vicente and A. Althammer, Org. Lett., 2008, 10, 2299-2302; (c) L. Ackermann and R. Vicente, Top. Curr. Chem., 2010, 292 211-229; (d) ruthenium-catalyzed directed arylations with phenols: L. Ackermann and M. Mulzer, Org. Lett., 2008, 10, 5043-5045.

10 L. Ackermann, A. Althammer and S. Fenner, Angew. Chem., Int. Ed., 2009, 48, 201-204.

11 For examples of direct arylations of pyridine $N$-oxides with aryl halides or triflates, see: (a) L.-C. Campeau, D. R. Stuart, J.-P. Leclerc, M. Bertrand-Laperle, E. Villemure, H.-Y. Sun, S. Lasserre, N. Guimond, M. Lecavallier and K. Fagnou, J. Am. Chem. Soc., 2009, 131, 3291-3306; (b) D. J. Schipper, M. El-Salfiti, C. J. Whipp and K. Fagnou, Tetrahedron, 2009, 65, 4977-4983; (c) S. H. Cho, S. J. Hwang and S. Chang, J. Am. Chem. Soc., 2008, 130, 9254-9256; (d) L.-C. Campeau, D. J. Schipper and K. Fagnou, J. Am. Chem. Soc., 2008, 130, 3266-3267; (e) H.-Q. Do and O. Daugulis, J. Am. Chem. Soc., 2007, 129, 12404-12405; (f) L.-C. Campeau, S. Rousseaux and K. Fagnou, J. Am. Chem. Soc., 2005, 127, 18020-18021; (g) K. Fagnou, Top. Curr. Chem., 2010, 292, 35-56; $(h)$ see also: H. Andersson, T. S.-L. Banchelin, S. Das, R. Olsson and F. Almqvist, Chem. Commun., 2010, 46, 3384-3386; (i) A. Larivee, J. J. Mousseau and A. B. Charette, J. Am. Chem. Soc., 2008, 130, 52-54; (j) K. S. Kanyiva, Y. Nakao and T. Hiyama, Angew. Chem., Int. Ed., 2007, 46, 8872-8874.

12 Under otherwise identical reaction conditions, a lower catalyst loading or reduced reaction temperatures provided less satisfactory yields.

13 Representative examples of direct arylations of oligofluoroarenes with aryl halides: (a) O. Rene and K. Fagnou, Org. Lett., 2010, 12, 2116-2119; (b) H.-Q. Do, R. M. K. Khan and O. Daugulis, J. Am. Chem. Soc., 2008, 130, 15185-15192; (c) M. Lafrance, C. N. Rowley, T. K. Woo and K. Fagnou, J. Am. Chem. Soc., 2006, 128, 8754-8756. 